\title{
Assessment of World Health Organization Collaborating Centres in the Eastern Mediterranean Region
}

\author{
Ahmed Mandil' ${ }^{1}$ Samar ElFeky ${ }^{7}$ and Arash Rashidian ${ }^{7}$
}

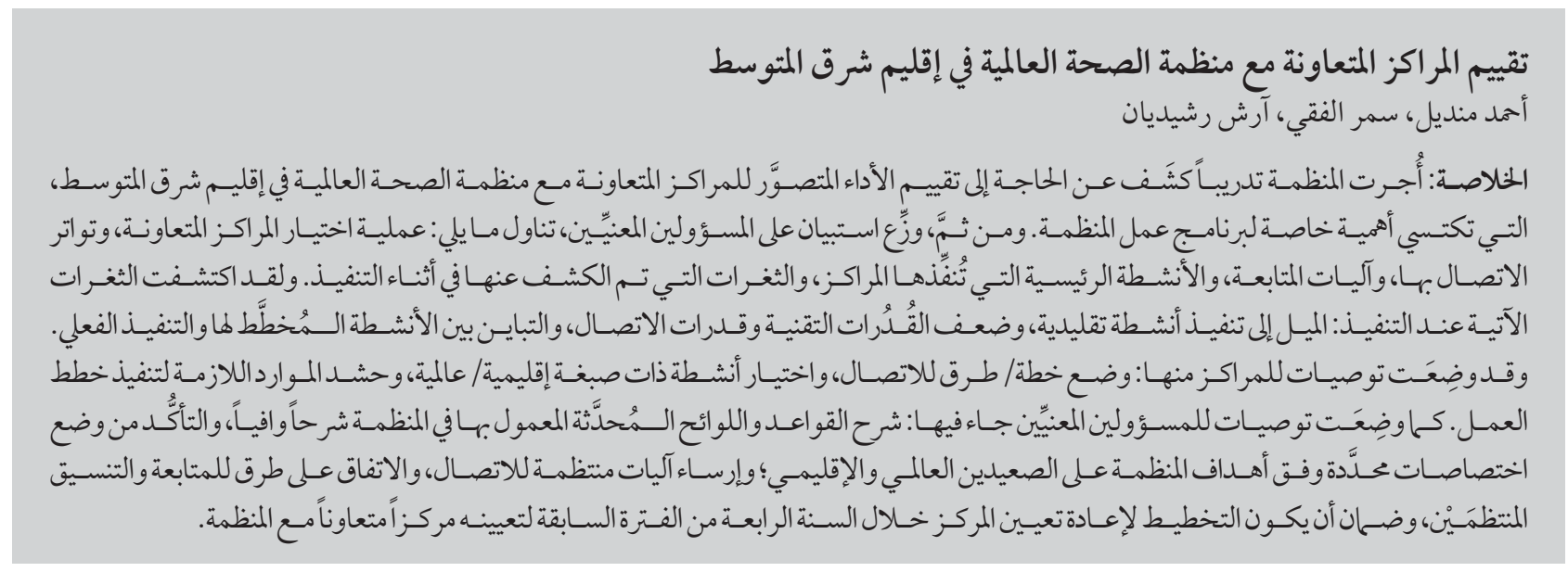

ABSTRACT Following in-house training, there was a need for assessing perceived performance of World Health Organization (WHO) collaborating centres in the Eastern Mediterranean Region, with special relevance to WHO's programme of work. Thus, a questionnaire was shared with responsible officers covering: selection process, frequency of communication, monitoring mechanisms, key delivered activities, and identified gaps during implementation. These included: tendency to implement regular activities, weak technical capacity and communication, and discrepancies between planned activities and actual implementation. Recommendations for centres included: establishing communication plan/modalities, selecting activities of global/regional nature, and mobilizing resources for work plan implementation. Recommendations for responsible officers included: carefully explaining updated WHO rules and regulations; ensuring that specific terms of reference are set as per WHO's global/regional mandates; setting up regular communication mechanisms; agreeing on regular monitoring and coordination modalities; and ensuring that redesignation planning takes place during the 4th year of prior designation period.

\section{Évaluation des Centres collaborateurs de I'OMS dans la Région de la Méditerranée orientale}

RÉSUMÉ Une formation en interne a mis en évidence la nécessité d'évaluer la perception de la performance par les Centres collaborateurs de l'OMS de la Région de la Méditerranée orientale, notamment en relation avec le programme de travail de l'OMS. Pour cette raison, un questionnaire a été communiqué aux responsables traitant de domaines tels que le processus de sélection, la fréquence de communication, les mécanismes de suivi, les activités clés proposées, et les lacunes identifiées pendant la mise en œuvre. II s'agissait notamment de la tendance à mettre en œuvre les mêmes activités, la faiblesse des capacités techniques et une mauvaise communication, un décalage entre les activités planifiées et la mise en œuvre réelle. Les recommandations adressées aux centres étaient les suivantes : établir un plan/ des modalités de communication ; sélectionner des activités à caractère mondial/régional ; et mobiliser des ressources pour la mise en ouvre du plan de travail. Les recommandations faites aux administrateurs responsables consistaient à expliquer clairement les règles et règlements actualisés de l'OMS, à garantir que les attribution spécifiques soient définies conformément aux mandats mondiaux/régionaux de l'OMS ; à mettre au point des mécanismes de communication courants ; à convenir de modalités de suivi et de coordination régulières ; et à assurer que les dispositions en vue des redésignations soient prises au cours de la quatrième année de la période initiale.

'Department of Information, Evidence and Research (IER), WHO Regional Office for the Eastern Mediterranean, Cairo, Egypt (Correspondence to: A. Mandil: mandila@who.int).

Received: 12/09/17; accepted: 26/10/17 


\section{Introduction}

World Health Organization (WHO) collaborating centres are institutions such as research institutes, parts of universities or academic institutions, designated by the WHO DirectorGeneral to carry out activities in support of WHO programmes (1). The collaborating centres support the achievement of planned strategic objectives at national and regional levels; enhance the scientific validity of the health work of the WHO collaborating centres; and develop and strengthen institutional capacity in countries and regions. All activities that WHO collaborating centres conduct under their designation should be jointly planned and implemented with $\mathrm{WHO}$, clearly linked to WHO strategic plans, and reflected in the work plans of the WHO technical programmes to which they contribute.

Currently, there are $>800 \mathrm{WHO}$ collaborating centres in $>80$ countries worldwide, of which, 44 are located in the Eastern Mediterranean Region (1). The centres located in the Region cover a wide range of areas of work, and are intended to support WHO work plans in capacity building and research and field activities related to: communicable diseases (rabies, HIV, tuberculosis and mycetoma); noncommunicable diseases (mental health, diabetes, cardiovascular diseases, osteoporosis, tobacco control, metabolic bone disorders, endocrine disorders, cancer education, gastrointestinal cancer, and substance use disorders); health policy and management; mass gatherings; nursing and midwifery; occupational health; nutrition and food technology; dental health; blood safety; pharmacovigilence; vision and hearing disabilities; and water and sanitation. The full list of the collaborating centres in the Region is accessible at http://apps.who.int/whocc/List. aspx?cc_region=EMRO\&).

To regulate the designation of the collaborating centres and planning for joint activities, 2 guidelines have been developed and are regularly updated by WHO: 1 is designed to assist prospective centres in their application for designation or redesignation processes (2); and the other is intended for WHO staff supervising the designated centres, whether in the capacity of responsible officers or technical counterparts (3).

During 2015, a WHO collaborating centres' assessment survey was conducted to obtain feedback from responsible officers in the Regional Office for the Eastern Mediterranean and heads of the centres in their perspective countries. The response rate of the assessment survey was $84 \%$ among responsible officers and 30\% among centre directors.

The assessment revealed key challenges and gaps and came up with recommended actions from both sides that were the basis for the discussion during the "Third Meeting of the WHO Collaborating Centres in the Eastern Mediterranean Region" that took place in Cairo, Egypt from 29 to 30 April, 2015.

As a result of an in-house training on WHO collaborating centres' rules and regulations in February 2016, a need was identified to assess the perceived performance of WHO collaborating centres in the Region, with special relevance to WHO's programmes of work during 2012-2015, and to identify monitoring modalities and implementation gaps in the Region for future work.

\section{Methodology}

An assessment exercise was conducted with support of WHO responsible officers in different technical units to provide their feedback, using a crosssectional approach. A questionnaire was designed and shared with responsible officers at all the 44 active centres. We aimed to collect feedbacks about the collaborative work between $\mathrm{WHO}$ and the centres during 2012-2015, with emphasis on setting collaborative areas of work related to WHO work plans and communication and monitoring modalities at the centres.

The assessment questionnaire covered the following items:

- selection process of the designated centres;

- frequency of communication with the WHO collaborating centres to discuss implementation of the agreed-upon work plan;

- monitoring mechanisms used for implementation of the agreed-upon activities;

- key activities, products and services that the WHO collaborating centres delivered during 2012-2015, in line with the agreed-upon work plan, related to WHO's programme of work within the corresponding specific area; and

- identified gaps during implementation of the action plan with relevant WHO collaborating centre, and actions that have been undertaken to overcome the gaps.

\section{Results}

Out of the 30 responsible officers for the 44 active WHO collaborating centres (some officers are responsible for $>1$ centre) who received the assessment tool, 26 completed the questionnaire on behalf of 41 WHO collaborating centres; that is, $41 / 44=93 \%$ response rate (taking into consideration the number of centres rather than the number of responding responsible officers).

Between 2012 and 2015, 16 (39\%) centres took the initiative to contact WHO to be designated as collaborating centres; 12 (29\%) centres were approached by $\mathrm{WHO}$; and for 14 (32\%) centres, it was not known who made the initial approach.

Regarding communication with the WHO collaborating centre, only $29.3 \%$ were contacted to discuss the implementation of the agreed-upon 


\begin{tabular}{lr}
\hline $\begin{array}{l}\text { Table } 1 \text { Monitoring mechanisms for WHO Collaborating Centres, Eastern } \\
\text { Mediterranean Region, 2012-2015 }\end{array}$ \\
\hline Categories & No. (\%) \\
Annual report & $85(85.4)$ \\
Visit by WHO to the centre & \\
Visit by WHO collaborating centres director/personnel to \\
WHO & $13(31.7)$ \\
Others & $14(34.0)$
\end{tabular}

Categories were not mutually exclusive, that is, > 1 answer was chosen by some respondents.

work plan, whenever there was a specific activity to follow up or a problem to resolve (Figure 1).

Almost all responsible officers considered the annual report as the most relevant monitoring mechanism (85.4\%), followed by occasional visits of WHO collaborating centre representatives to WHO during meetings and workshops (31.7\%) (). Only 8 centres (19.5\%) were reported to be monitored by their corresponding responsible officers through follow-up visits to the centres.

Most activities conducted by WHO Eastern Mediterranean Region collaborating centres were reported by responsible officers to be broadly linked to
WHO functions and work plans during 2012-2015, including: development of regional strategies, technical support and capacity building, advocacy, development and dissemination of evidence. However, some responsible officers stated that the activities of the $\mathrm{WHO}$ collaborating centres were not considered relevant to $\mathrm{WHO}$ work plans and focused on national activities rather than regional scope of work.

Responsible officers identified some gaps during implementation of the joint work plans with the WHO collaborating centres including: logistical difficulties during implementation of planned activities at the national level; greater tendency to implement regular activities of the institution rather than regionally focused activities; weak technical capacity of the centre over time; lack of communication; effects of emergency situations on implementation of the work plan; need of revisiting the terms of reference; and discrepancies between the planned activities and actual implementation.

\section{Discussion}

A WHO collaborating centre is an institution designated by the WHO Director-General to carry out activities in support of WHO's programmes (1). The collaborating centres support the achievement of planned strategic objectives at national and regional levels (1). The findings of the assessment survey of the contribution of the Eastern Mediterranean Region WHO collaborating centres to the WHO programme of work reflect some gaps that need action at WHO and collaborating centre levels. Addressing such gaps will lead to better collaboration with the centres and a more beneficial impact of their work

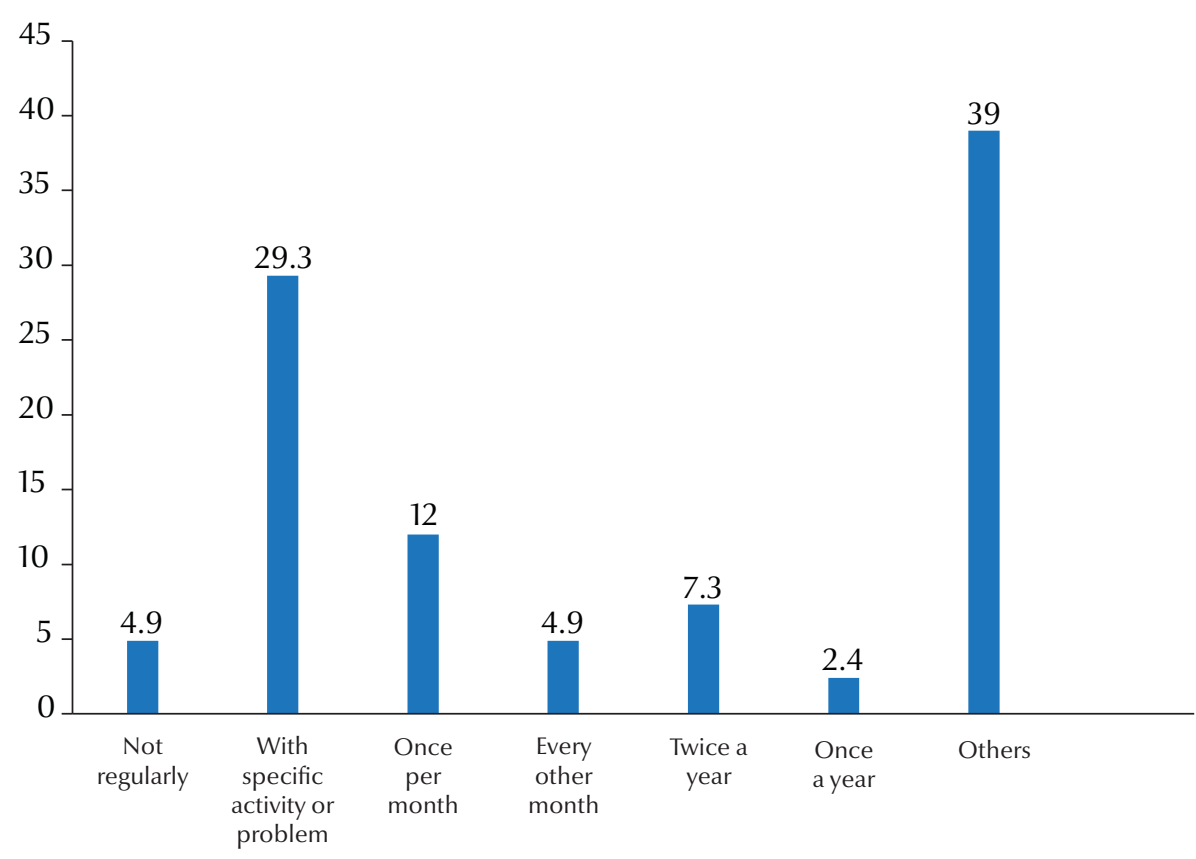


on implementing WHO work plans. Enhancing the role of WHO in identifying potential centres to be designated as WHO collaborating centres will widen the scope of collaboration between WHO and active centres. The survey also revealed the need for ensuring that the activities have a regional/global perspective rather than regular work at a national level. Continuous communication between the designated centres and WHO should be ensured during work plan implementation for timely addressing any challenges/constrains and refining as needed. Feedback of the heads/focal points of the WHO collaborating centres within institutions in the Region to the survey results is needed to establish specific modalities to address the identified challenges/ constraints, tangible solutions, and plans of action.

\section{Conclusion}

WHO technical units need to consider centres that have the potential to be WHO collaborating centres and start collaboration with them as a prerequisite for designation rather than waiting for them to contact WHO. The assessment also concluded that there is lack of regular communication with the centres and limited follow-up of specific activities or problem solving. While most activities of the WHO collaborating centres during 2012-2015 were reported to be broadly linked to WHO functions and work plans, some activities were not considered relevant to WHO work plans and focused on the national rather than regional scope of the work. Identified gaps and challenges that face responsible officers during their collaboration with the WHO collaborating centres include a tendency to implement regular activities of the institution rather than regional activities, as well as the influence of emergency situations in some countries on implementation of work plans.

\section{Recommendations for WHO collaborating centres}

1. Establishing communication plan and modalities between the centre and WHO (especially responsible officers and technical counterparts) during implementation of the work plan, for timely discussion of challenges and constraints to establish concrete and applicable solutions;

2. selecting the activities to be included in the work plan with the WHO collaborating centre that are global/regional in nature, rather than regular/subnational/ national activities;

3. mobilizing resources: logistic/ technical/fiscal for implementing the agreed work plan; and

4. providing technical support to develop capacity of the centres whenever needed to improve performance and scope of collaboration.

\section{Recommendations for responsible officers}

1. Providing the $\mathrm{WHO}$ collaborating centre with updated WHO rules and regulations by disseminating information and conducting field visits;

2. ensuring that specific terms of reference are established in accordance with WHO's global/regional mandates;

3. discussing the gaps with the $\mathrm{WHO}$ collaborating centre to establish joint actions through conducting regular meetings and field visits;

4. setting up better/regular communication plans and mechanisms, through which different queries and matters are handled;

5. closely following up implementation of plans with the WHO collaborating centres, and early management of implementation problems, through efficient communication channels;

6. agreeing upon regular monitoring modalities, including visiting the centres on a regular basis;

7. strengthening coordination mechanisms;

8. engaging WHO collaborating centres in regional meetings/consultations and WHO global fora; and

9. ensuring that redesignation planning takes place as early as possible during the 4th year of the prior designation period.

\section{References}

1. WHO Collaborating Centres. Global database. (http://apps. who.int/whocc/List.aspx?cc_region=EMRO\&, accessed 8 November 2017).

2. Guide for WHO collaborating centres. Geneva: World Health Organization; 2016 (http://www.who.int/collaboratingcentres/Guide_for_WHO_collaborating_centres_2016.pdf?ua=1, accessed 8 November 2017).
3. Guide for $\mathrm{WHO}$ staff working with $\mathrm{WHO}$ collaborating centres. Geneva: World Health Organization; 2016 (http://www. searo.who.int/entity/research_policy/documents/guide-forworking-with-wcc.pdf?ua=1, accessed 8 November 2017). 